\title{
The Effect of Rolling and Crimping on Cell-Seeded Synthetic Scaffolds for the Development of Transcatheter Valves by Tissue Engineering
}

\author{
Magdalena Scheuer ${ }^{1}$, Trixi Hollweck ${ }^{1}$, Renè Bombien ${ }^{1}$, Ulrike Haas ${ }^{1}$, Eva Bartok ${ }^{2}$, Cornelia Fano ${ }^{3}$, Martin \\ Dauner ${ }^{3}$, Christoph Schmitz ${ }^{1}$, Bruno Reichart ${ }^{1} \&$ Bassil Akra ${ }^{1}$ \\ ${ }^{1}$ Department of Cardiac Surgery, Medical Center Munich University, Marchioninistraße Munich, Germany \\ ${ }^{2}$ Chair of Medical Engineering, Technical University Munich, Boltzmannstrasse Garching, Germany \\ ${ }^{3}$ Institute of Textile Technology and Process Engineering, Körschtalstraße Denkendorf, Germany \\ Correspondence: Bassil Akra, Department of Cardiac Surgery, Medical Center Munich University, \\ Marchioninistraße 15, 81377 Munich, Germany. Tel: 49-089-7095-6465. E-mail: \\ bassil.akra@med.uni-muenchen.de
}

Received: February 25, 2012 Accepted: March 23, 2012 Online Published: May 8, 2012

doi:10.5539/jmsr.v1n3p1 URL: http://dx.doi.org/10.5539/jmsr.vln3p1

This work was sponsored by the Federal Ministry of Education and Research (FKZ: 01EZ1107A)

\begin{abstract}
Transcatheter valve replacement using bioprosthetics is a common procedure, however limited due to graft durability. The aim of this study was to verify the mechanical durability of tissue engineered constructs to crimping necessary for transcatheter deployment. Polyurethane patches were seeded with human vascular cells. Mechanical stress of transcatheter methods was simulated by rolling and crimping. Seeded patches were rolled using a patch-rolling device. For crimping, seeded patches were fixed on a polymer stent and crimped by a conventional crimper. Effect of mechanical strain on cellular coating was analyzed by scanning electron microscopy (SEM), immunocytochemistry (ICC) and immunohistochemistry (IHC). SEM analysis of stressed patches showed a confluent cellular coating. ICC and IHC demonstrated the integrity of cellular layers after rolling and crimping. Mechanical stress does not affect the stability of colonized cells on polyurethane patches. This demonstrates the feasibility of applying tissue-engineering methods for the development of seeded transcatheter heart valves.
\end{abstract}

Keywords: tissue engineering, polyurethane, valve replacement, transcatheter, crimping, heart valve disease

\section{Introduction}

The standard therapy of valvular diseases is heart valve replacement (Bleiziffer et al., 2009). For high-risk patients, unsuitable for conventional open surgery, transapical valve replacement by biological valves is a treatment being more and more in common use (Bleiziffer et al., 2009; Conradi et al., 2012; ElBardissi, Shekar, Couper, \& Cohn, 2011). It enables a minimal-invasive intervention instead of conventional therapies using heart-lung machine and sternotomy (Kempfert et al., 2011). However, biological valves are limited due to their durability. Moreover, these prostheses are not able to rebuild and repair themselves (Yacoub et al., 1995). The main disadvantage of continuous degeneration of glutaraldehyde-fixed xenograft valves is the loss of the mechanical features of the valves right up to valve failure. Especially for younger patients this is one of the main problems (Sodian et al., 2000). Tissue engineered synthetic heart valves may provide a new innovative solution. Synthetic scaffolds can be produced easily and are therefore not limited. Features of the material are adjustable in the manufacturing process depending on the application. For tissue engineering, important features are biocompatibility and bioresorbability without producing toxic products and after the seeded cells have created their own cell-matrix. Benefits of vital tissue-engineered heart valves include a reduced risk for infections and thrombogenicity (Chapekar, 2000; Lalan, Pomerantseva, \& Vacanti, 2001; Mendelson \& Schoen, 2006; Shinoka, 2002). A porous macro-structure is essential for cell attachment, interaction, proliferation and matrix creation. The patient's own vascular cells can be used as the cover of the synthetic material (Mendelson \& Schoen, 2006; 
Shinoka, 2002). This would presumably prevent immune response. Furthermore, degeneration of tissue engineered valves should be less progressive than those of biological valves based on the vital tissue (Weber et al., 2011). For transapical valve replacements stented valves have to be compressed by a crimper onto a balloon-catheter leading the valve whilst implantation (McVeigh et al., 2006). The valve has to sustain the pressure of compressing for the whole procedure time (Walther et al., 2007). The aim of this study was to verify the immediate mechanical durability of tissue engineered synthetic materials to crimping stress.

\section{Materials and Methods}

\subsection{Cell Isolation and Cell Culture}

Endothelial cells (ECs) and fibroblasts (FBs) were isolated from human saphenous vein segments as previously described (Fischlein et al., 1994; Haegerstrand, Gillis, \& Bengtsson, 1992). Briefly, remaining parts of saphenous vein segments used for bypass operations were collected and stored in M199 media at $4{ }^{\circ} \mathrm{C}$ for $1-5 \mathrm{~d}$ before tissue processing. For ECs isolation, human saphenous vein segments $(9.5 \pm 5.3 \mathrm{~cm})$ were cannulized and incubated with $0.8 \mathrm{mg} / \mathrm{ml}$ collagenase II (Worthington Biochemical Corp., Lakewood, NJ, USA) in human serum albumin (Baxter Deutschland $\mathrm{GmbH}$, Unterschleißheim, Germany) for $30 \mathrm{~min}$ at $37^{\circ} \mathrm{C} / 5 \% \mathrm{CO}_{2}$. For $\mathrm{FBs}$ isolation, cannulized vein segments were subsequently incubated with $2 \mathrm{mg} / \mathrm{ml}$ collagenase for $40 \mathrm{~min}$ at $37^{\circ} \mathrm{C} /$ $5 \% \mathrm{CO}_{2}$. The obtained ECs and FBs solutions were cultured in Primaria ${ }^{\mathrm{TM}}$ culture flasks $\left(12.5 \mathrm{~cm}^{2}\right.$, Corning Incorporated, NY, USA) in endothelial cell growth medium and fibroblast growth medium (PromoCell GmbH, Heidelberg, Germany), respectively at $37^{\circ} \mathrm{C} / 5 \% \mathrm{CO}_{2}$. Medium was changed every 2-3 days. ECs and FBs were passaged at confluency.

\subsection{Phenotypic Characterization of ECs and FBs}

Phenotypic characterization of ECs and FBs was performed by morphological classification using phase contrast microscopy (Carl Zeiss Mikrolmaging GmbH, Göttingen, Germany). ECs were identified by typical cobblestone morphology. FBs were identified by a characteristic elongated spindle-shaped appearance with several extensions. Additionally, characterization of EC and FB was performed by immuncytological analysis. For verification of ECs and FBs, cells were stained against CD31 (2.72 $\mu \mathrm{g} / \mathrm{ml}$, dilution 1:20, Dianova GmbH, Hamburg, Germany) and TE-7 $(0.1 \mathrm{mg} / \mathrm{ml}$, dilution 1:150, Millipore Corporation BioScience Division, Temecula, CA, USA), respectively according to manufacturer's protocol using HRP Detection System (Biozol GmbH, Eching, Germany). Briefly, cells were seeded in culture slides (BD Biosciences, Bedford, USA). After cell confluence, cells were fixed and stored in $96 \%$ ethanol (Merck KGaA, Darmstadt, Germany) at $-80{ }^{\circ} \mathrm{C}$. For staining, chambers were washed with PBS (Biochrom AG, Berlin, Germany) and blocked for endogenous peroxidase. Primary antibody was incubated for $30 \mathrm{~min}$. Afterwards, chambers were washed and covered with biotinylated link for $10 \mathrm{~min}$ as well as HRP-Streptavidin label for $10 \mathrm{~min}$, followed by AEC peroxidase substrate kit (Vector Laboratories, Inc., Burlingame, CA, USA) staining for $10 \mathrm{~min}$. All steps were incubated at room temperature. Finally cell nuclei were stained with haematoxylin (1:4 in PBS (Biochrom AG, Berlin, Germany), Merck KGaA, Darmstadt, Germany). Controls for non-specific binding of biotinylated link were performed by excluding primary antibody. Samples were observed using bright field microscopy (Carl Zeiss Mikrolmaging GmbH, Göttingen, Germany).

\subsection{Scaffold Type}

Scaffolds were produced by spraying non-degradable polyurethane (PU, patent DE $2806030 \mathrm{C} 2$ ) filaments to form sheets with a thickness of $0.3 \mathrm{~mm}$. Randomly orientiated PU fibres offer a median diameter of $1.55 \mu \mathrm{m}$. For seeding procedure, PU patches with a length of $55 \mathrm{~mm}$ and a width of $18 \mathrm{~mm}$ were sterilized by formaldehyde deposition at $60-70^{\circ} \mathrm{C}$ for $7 \mathrm{~h}$.

\subsection{Seeding Procedure}

For reproducible seeding, the seeding area on patches was pre-defined by using Teflon ${ }^{\circledR}$ cylinders with a height of $1.10 \mathrm{~cm}$, an outer diameter of $1.50 \mathrm{~cm}$ and an inner diameter of $1.13 \mathrm{~cm}\left(\mathrm{~A}=1 \mathrm{~cm}^{2}\right.$, manufactured in-house). FBs and ECs $\left(1.5 \times 10^{6}\right.$ cells $\left./ \mathrm{cm}^{2}\right)$, respectively were introduced into the Teflon ${ }^{\circledR}$ cylinders placed centred on the patches (Figure 1a). After $4 \mathrm{~d}$ incubation per cell type, seeded scaffolds were mechanically stressed by rolling and crimping procedures. 

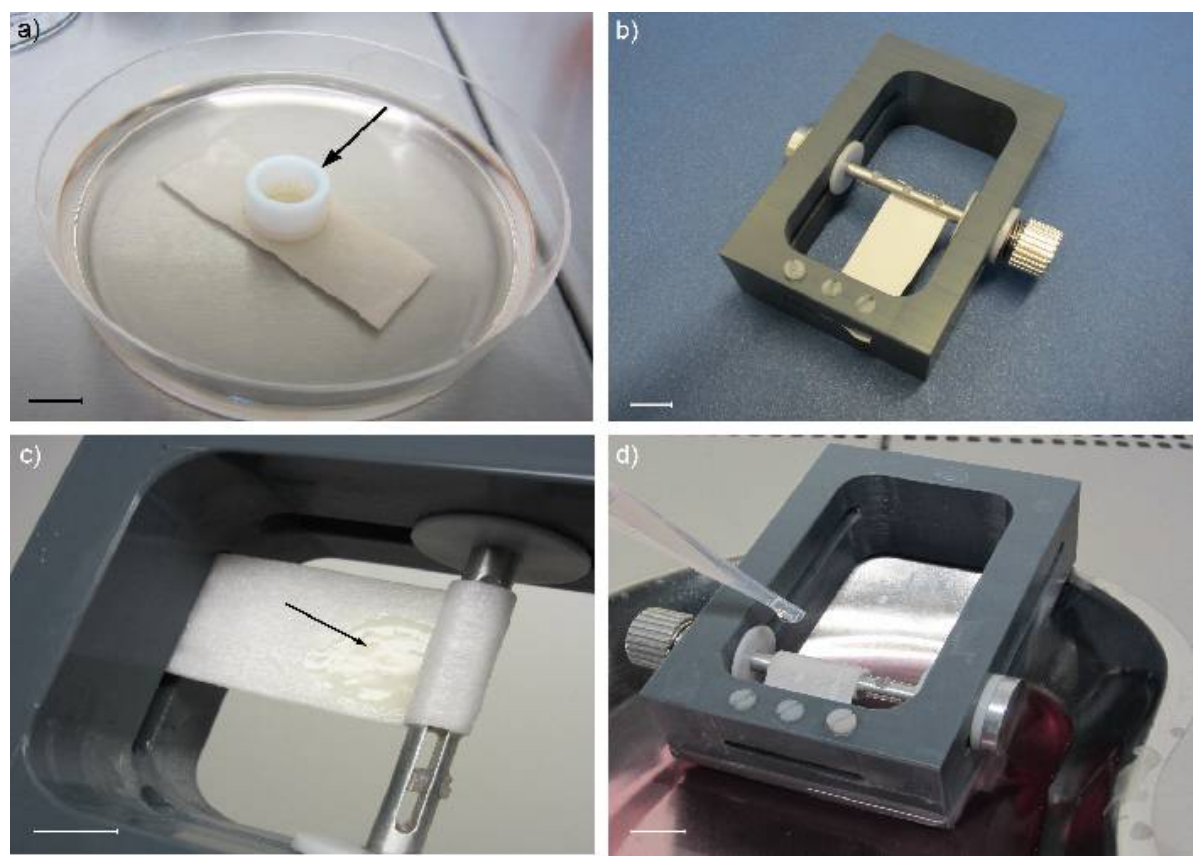

Figure 1. Static seeding of polyurethane scaffolds and rolling procedure. Teflon ${ }^{\circledR}$ cylinders (arrow) with a height of $1.10 \mathrm{~cm}$, an outer diameter of $1.50 \mathrm{~cm}$ and an inner diameter of $1.13 \mathrm{~cm}$ were placed on scaffolds $(\mathrm{A}=55 \mathrm{~mm} \times 18$ $\mathrm{mm}$ ) for reproducible static seeding procedure. FBs and ECs were introduced into the Teflon ${ }^{\circledR}$ cylinders. After $4 \mathrm{~d}$ incubation per cell type, seeded scaffolds were exposed to mechanical stress. In a patch rolling device $(10 \mathrm{~cm} \times 6$

$\mathrm{cm}$ ) the seeded patch was fixed with bolts on both sides. The seeded area was either turned clockwise or anti-clockwise and therefore squeezed and stretched. a) Static seeding of polyurethane scaffold. Arrow on Teflon ${ }^{\circledR}$ cylinder b) Patch-rolling device with fixed patch. c) Rolling procedure. Seeded area (arrow) is turned to get squeezed. d) Moisturizing of the patch during time intervals in rolled position. Scale bars $=1 \mathrm{~cm}$

\subsection{Mechanical Stress Tests on Seeded Patches}

\subsubsection{Rolling Procedure}

Patches $(n=72)$ for rolling procedure were divided into three groups. Group A and B were seeded with FBs. Group C was initially seeded with FBs and subsequently seeded with ECs. Patches $(n=60)$ of all groups were rolled over a metal rod by using a newly developed patch-rolling device (Figure 1b). In group A, seeded patch surface was rolled clockwise. In group B and C, seeded patch surface was rolled anti-clockwise (Figure 1c). Patches were maintained in rolled position for $0 \mathrm{~min}$ (simply rolled up and rolled out), $1 \mathrm{~min}, 2 \mathrm{~min}, 3 \mathrm{~min}$ and 4 min. During time intervals, rolled patches were moisturized with growth medium in which the patches had been cultured (Figure 1d). Patches $(n=12)$ without mechanical stress served as positive controls for confluent seeding.

\subsubsection{Crimping Procedure}

For patch crimping, patches $(\mathrm{n}=16)$ were fixed with a surgical suture on a polymer stent $(\mathrm{Size}=6.5 \mathrm{~cm} \times 2.5$ $\mathrm{cm}$, thickness $=1.1 \mathrm{~mm}$; Figure 2a and b). FBs- and ECs-seeded patches (Figure 2c) were crimped for $5 \mathrm{~min}, 10$ $\mathrm{min}$ and $30 \mathrm{~min}$ to a diameter of $10 \mathrm{~mm}$ in a conventional heart valve crimper (Figure 2d; Size 29, Edwards Lifesciences SAS, Unterschleißheim, Germany). During crimping, patches were moisturized (Figure 2e) with growth medium in which patches were cultured. After crimping, stented patches dilated independently and were prepared for analysis. Seeded patches $(n=4)$ without crimping served as positive controls for confluent seeding. 

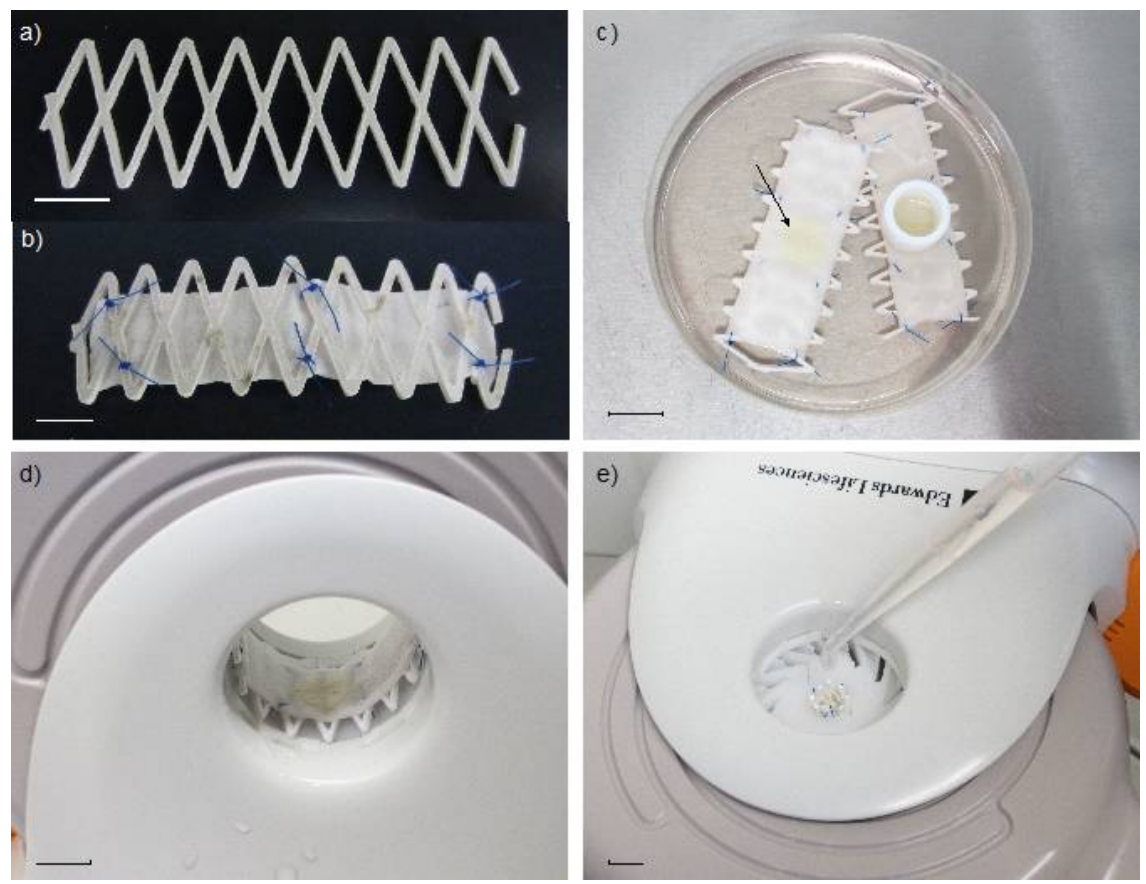

Figure 2. Stented patch and crimping procedure. Patches were fixed on stents with surgical sutures. After static seeding with FBs and ECs, stented patches were put into a crimper. Patches were compressed and stayed crimped for different time intervals (5,10 and $30 \mathrm{~min})$. a) Lasered polymer stent with a length of $6.5 \mathrm{~cm}$, a width of $2.5 \mathrm{~cm}$. and a hight of $1.1 \mathrm{~mm}$. b) Fixed patch c) Static seeding of stented polyurethane patch using a Teflon ${ }^{\circledR}$ cylinder for reproducible seeding area (arrow). d) Patch in crimper before crimping procedure. e) Moisturizing of compressed patch during crimping procedure. Scale bars $=1 \mathrm{~cm}$

\subsection{Analysis}

\subsubsection{Scanning Electron Microscopy (SEM)}

In order to assess the mechanical integrity of the cellular coating, seeded patches were fixed in Fix II (Consisting of $456 \mathrm{ml}$ aqua bidest (Ampuwa, Fresenius Kabi Deutschland GmbH, Bad Homburg v. d. H., Germany), $0.75 \mathrm{ml}$ $1 \mathrm{~N}$ hydrochloric acid (Titrisol, Merck KGaA, Darmstadt, Germany), $43.5 \mathrm{ml}$ glutaraldehyd (Sigma-Aldrich Chemie GmbH, Steinheim, Germany) and $5.65 \mathrm{~g}$ sodium cocodylate trihydrate (Sigma-Aldrich Chemie GmbH, Steinheim, Germany)) at $4{ }^{\circ} \mathrm{C}$ for $48 \mathrm{~h}$. Seeded patches were dehydrated in an afferent ethanol series $(30 \%, 50$ $\%, 70 \%$ and $96 \%$ EtOH) and subsequently in $100 \%$ acetone (Merck KGaA, Darmstadt, Germany). After sample drying at the critical point, patches were sputtered with gold films for $180 \mathrm{~s}$ at $10^{-5} \mathrm{mbar}$ and analyzed microscopically by using a scanning electron microscope (SEM; Carl Zeiss Mikrolmaging GmbH, Göttingen, Germany).

\subsubsection{Immunocytochemistry (ICC)}

The confluence of cell-seeding - especially ECs layers - was analyzed by intracellular staining of von Willebrand factor (vWF) and nuclei staining with diamidinophenylindole (DAPI). Seeded scaffolds were fixed with methanol-acetone (1:1, Merck KGaA, Darmstadt, Germany) at room temperature for 2 min and rinsed with PBS (Biochrom AG, Berlin, Germany). Samples were incubated with a primary polyclonal rabbit antibody against human vWF ( $40 \mu \mathrm{g} / \mathrm{ml}$, Sigma-Aldrich GmbH, Hamburg, Germany) at $37^{\circ} \mathrm{C}$ for $45 \mathrm{~min}$. After washing with PBS, seeded scaffolds were incubated $30 \mathrm{~min}$ at $37{ }^{\circ} \mathrm{C}$ with secondary antibody goat anti rabbit IgG, Fluoresceinisothiocyanat (FITC) conjugate $(22 \mu \mathrm{g} / \mathrm{ml}$, Sigma-Aldrich GmbH, Hamburg, Germany). Antibodies were diluted in PBS/10 \% FCS. Samples were washed with PBS and cell nuclei were stained with $1 \mu \mathrm{g} / \mathrm{ml}$ DAPI (Roche GmbH, Mannheim, Germany) in PBS for $20 \mathrm{~min}$ at room temperature. Seeded scaffolds without mechanical strain served as positive controls. Controls for non-specific binding of secondary antibodies were performed by excluding primary antibodies. For fluorescence microscopy, seeded scaffolds were covered with PBS and signals were detected using a computer-guided fluorescence microscope (Carl Zeiss Mikrolmaging 
GmbH, Göttingen, Germany). The excitation and emission of FITC conjugated antibodies was $495 \mathrm{~nm}$ and 517 $\mathrm{nm}$, respectively. Sample and control of non-specific binding of secondary antibodies were measured at identical exposure times.

\subsubsection{Immunohistochemistry (IHC)}

For distinction of FBs and ECs layers on PU, each cell type was determined by IHC. Fixation procedure of seeded scaffolds was performed in $4 \%$ formaldehyde (Microcos $\mathrm{GmbH}$, Garching, Germany) for $10 \mathrm{~d}$ at $4{ }^{\circ} \mathrm{C}$. Subsequently, fixed samples were paraffin-embedded and sectioned at $10 \mu \mathrm{m}$. For verification of ECs and FBs, sections were stained against CD31 $(2.72 \mu \mathrm{g} / \mathrm{ml}$, dilution 1:30, Dianova GmbH, Hamburg, Germany) and TE-7 $(1 \mathrm{mg} / \mathrm{ml}$, dilution 1:50, Millipore Corporation BioScience Division, Temecula, CA, USA), respectively according to manufacturer's protocol using HRP Detection System (Biozol GmbH, Eching, Germany). Briefly, specimens were blocked for endogenous peroxidase and were incubated with primary antibody overnight at 4 ${ }^{\circ} \mathrm{C}$. After washing with PBS, samples were incubated with biotinylated link for $10 \mathrm{~min}$ and HRP-Streptavidin label for $10 \mathrm{~min}$, followed by AEC peroxidase substrate kit (Vector Laboratories, Inc., Burlingame, CA, USA) staining for $10 \mathrm{~min}$. Finally cell nuclei were stained with alum hematoxylin (1:4 in PBS (Biochrom AG, Berlin, Germany), Merck KGaA, Darmstadt, Germany). Controls for non-specific binding of biotinylated link were performed by excluding primary antibody. Sections were examined using bright field microscopy (Carl Zeiss Mikrolmaging GmbH, Göttingen, Germany).

\section{Results}

\subsection{Mechanical Durability of Cellular Coating after Rolling Procedure}

In all groups, SEM showed high colonization efficiency in the predefined seeding area. After rolling up to 4 min, $85 \%$ of patches from Group A (FBs-seeded surface rolled to the outside; $\mathrm{n}=20$ ) showed a confluent cell layer (Figure 4a). Within this time interval, all patches from Group B (FBs-seeded surface rolled to the inside; $n=20$ ) revealed a confluent cellular coating. All outcomes of these groups were comparable to seeded patches without rolling stress. All FBs- and ECs-seeded patches (Group C, $n=20$ ) showed a great cell covering of the PU. Cell nuclei staining (Figure 4b; DAPI, blue) indicated a continuous layer of cells. The green perinuclear granula signified a confluent cell-layer of ECs (Von Willebrand factor, green) on almost all specimens. IHC revealed great cell-attachment and ingrowth of FBs and ECs to polymer on the majority of the patches. FBs formed various layers (Figure 3d) on which ECs (Figure 4c) were able to colonize. The examination of the mechanically stressed patches showed similar results to the positive controls without mechanical stress (Figure 3c-e). On almost all specimen ECs are seen confluent on top of FBs layer. FBs had an attachment with $100 \%$.

\subsection{Mechanical Durability of Cellular Coating after Crimping Procedure}

SEM showed a high colonization efficiency in the predefined seeding areas of all crimped patches $(\mathrm{n}=12)$. All Patches with 10 and 30 min of holding time showed a confluent cell-attachment (Figure 5a). Crimped patches with $5 \mathrm{~min}$ of holding time were confluently seeded with partial damage of the ECs-layer less than $50 \%$. Crimped scaffolds $(\mathrm{n}=12)$ showed equal confluence in all specimen in ICC (Figure 5b). Stained cell nuclei (DAPI, blue) covered the whole specimen. ECs (Von-Willebrand-Factor, green perinuclear granula) attached to FBs and showed confluence. IHC revealed partial damage of seeded cell layer (Figure $5 \mathrm{c}$ and d), especially scaffolds with 30 min holding time. Regarding the remaining samples, FBs formed a great layer with good ECs-attachment to the polymer of the scaffold. 

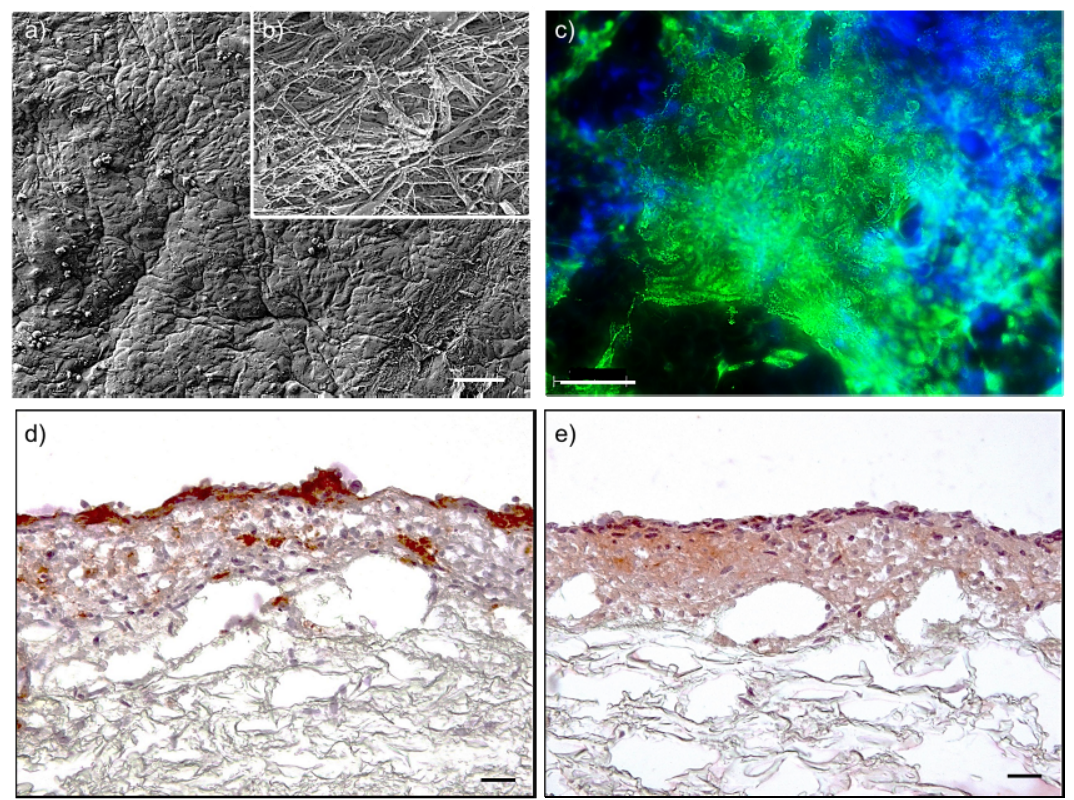

Figure 3. Positive control of scaffolds seeded with ECs and FBs. a) SEM revealed confluency and the characteristic cobblestone mono-layer of ECs. b) In comparison, non-degradable polyurethane (PU) scaffold without seeding: PU fibres offer diameters between $100 \mathrm{~nm}-550 \mathrm{~nm}$. c) ICC. Confluent cell-cover visible by cell-nuclei staining with DAPI (blue). ECs are stained with von Willebrand factor (green perinuclear granula) and covered most of the specimen. d) and e) IHC. ECs staining with CD31-antibody (d, brown). Homogenous ECscoverage and-attachment on top and within FBs layer. FBs staining with TE-7-antibody (e, red). FBs formed various layers with ingrowth into the scaffold. These are representatives of four independent experiments in quadruplicates. Scale bars: $\mathrm{a}-\mathrm{c}=100 \mu \mathrm{m} ; \mathrm{d}$ and $\mathrm{e}=80 \mu \mathrm{m}$
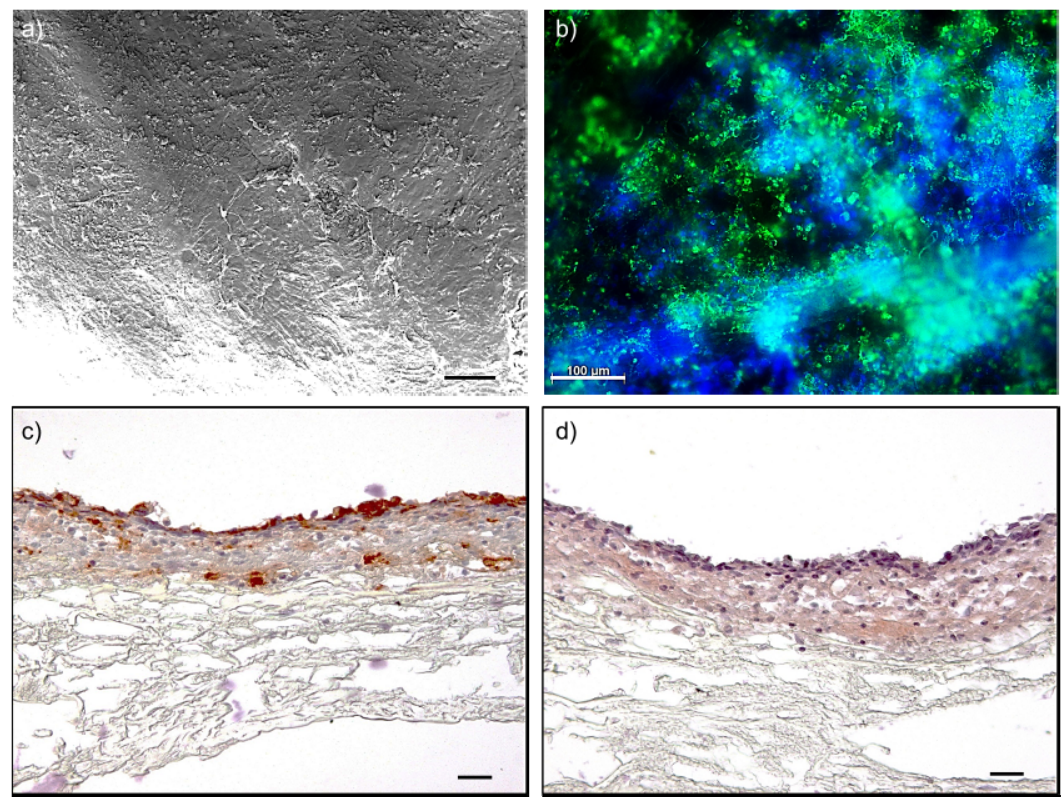

Figure 4. Analysis of seeded patches after rolling procedure. a) SEM. FBs- and ECs-seeded patches rolled anti-clockwise for 4 min demonstrated a partial damage on endothelialization with an intact FBs-layer underneath. b) ICC. vWF staining revealed a partial cover of ECs (green perinuclear granula) on a confluent FBs layer. All nuclei are stained with DAPI (blue) c) and d) IHC. CD31 staining (brown) of ECs (c) and TE-7 staining (red) of FBs (d) demonstrating a confluent cellular coating after rolling stress. Cell nuclei are stained by haematoxylin (purple). These are representatives of three independent experiments in quadruplicates. Scale bars: $\mathrm{a}$ and $\mathrm{b}=100 \mu \mathrm{m} ; \mathrm{c}$ and $\mathrm{d}=80 \mu \mathrm{m}$ 

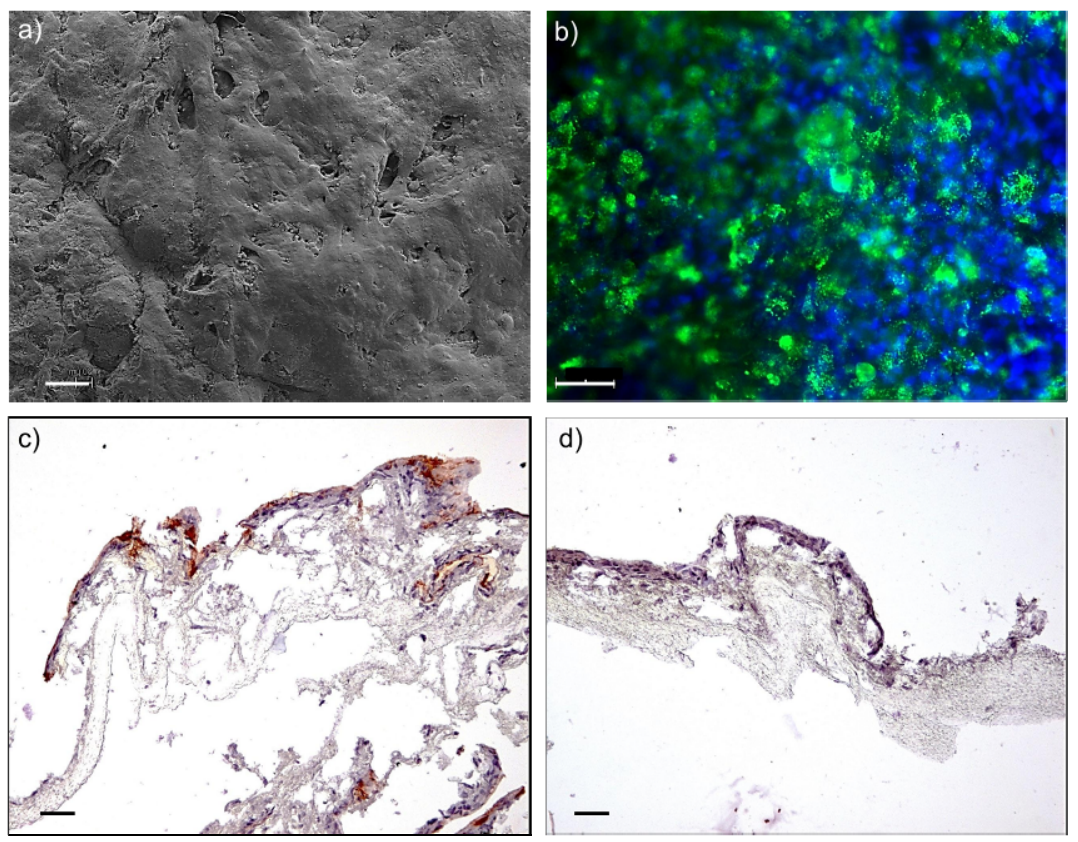

Figure 5. Analysis of seeded patches after crimping procedure. Scaffolds were crimped for 5, 10 and 30 min of holding time. a) SEM. No flaws and fragments were visible. Whole seeded area showed confluence. b) ICC. All specimens were covered with cells visible by staining cell-nuclei with DAPI (blue). ECs are stained against von Willebrand factor (green perinuclear granula) and covered fully the seeded area. c) and d) IHC. CD31 staining of ECs (c, brown) and TE-7 staining of FBs (d, grey) demonstrated a partial damage of cellular coating after crimping stress. Cell nuclei are stained by haematoxylin (purple). These are representatives of an experiment in quadruplicates after 30 min holding time. Scale bars: $\mathrm{a}=100 \mu \mathrm{m}, \mathrm{b}=50 \mu \mathrm{m}, \mathrm{c}$ and $\mathrm{d}=90 \mu \mathrm{m}$

\section{Disussion}

Tissue-engineered synthetic heart valves have been in research for some time past (Akhyari et al., 2011; Vacanti, 2006) and minimal invasive valve replacement has been in the ascendant recently (Higgins et al., 2011; Raja \& Navaratnarajah, 2009). Combining tissue-engineering and minimal-invasive methods in heart surgery would be a new milestone in therapy of valvular disease. The aim of this study was to verify the stability of tissue-engineered constructs regarding mechanical pressure which constitutes a first step towards transapical tissue-engineered valve replacement. Tissue engineered pulmonary valves have been already implanted in animals and the analyses showed great outcomes regarding the tissue stability (Jux et al., 2002; Kiefer et al., 2011). During these pre-clinical tests conventional biological valves were combined with stents for transcatheter implantation methods.

In this study, we have evaluated the possibility of developing a new generation of transcatheter heart valve. For this aim, synthetic polyurethane scaffolds were seeded with cells and exposed to two different kinds of mechanical stress (rolling and crimping) over different defined time intervals. Due to the cylindric design of the main compartment of rolling device, all seeded cells are equally subjected to rolling forces. Crimping also results in mechanical stress of the entire construct because of the massive modified scaffold geometry during crimping. Rolling showed the stability and integrity of seeded cell-layer enduring mechanical stress in squeezing and stretching. Stented patches were used to simulate the crimping procedure up to $30 \mathrm{~min}$ holding time.

Rolling patches for different holding times ( $0 \mathrm{~min}, 1 \mathrm{~min}, 2 \mathrm{~min}, 3 \mathrm{~min}, 4 \mathrm{~min}$ ) had no significant effect on the confluence and structural integrity, neither had the way of turning (anti-/clockwise). However, the stented patches crimped for five minutes showed under SEM a layer of collapsed cells on the surface whereas IHC showed a confluent thick FBs-layer indicating the endothelial layer being destroyed. In contrast, the stented patches crimped for 10 minutes presented good cell coverage with FBs- and ECs-layer under SEM and IHC. The patches crimped for 30 minutes showed a decreased thickness of FBs-layer and a partially present ECs-layer under IHC. As stated in other studies, cell and cell-matrix viability decreases with the amount of pressure and holding time (Lutter et al., 2010; Metzner et al., 2010). 
In the research for closure possibilities of atrial septal defects, simulated deliveries with FBs pre-seeded devices showed in vitro small areas of damaged or detached cells after mechanical stress. The remaining cells proliferated in subsequent culture and thus restored the confluent layer to the level of the control group (Raja \& Navaratnarajah, 2009). Such behaviour may also restore the degraded FBs-layers on the crimped patches. Tissue-engineered valves can remodel and grow with the organism (Cebotari et al., 2006). This was shown in a clinical study, where an acellular allograft matrix was seeded with mono-nuclear cell from peripheral blood and implanted via conventional heart surgery in children. In the following years, the annulus of the pulmonary valve enlarged with the growing child (Cebotari et al., 2006).

In the study about atrial septal defect occluders, implants for animals were only seeded with FBs. Despite the missing ECs-layer, no signs of thromboembolic lesions were found in any organs after implantation (Jux, et al., 2002). In a further study about minimally-invasive autologous tissue-engineered heart valve, an by crimping damaged endothelialization of the in-vivo valve did not cause any thromboembolic events (Schmidt et al., 2010). Therefore, a damaged or missing ECs-layer does not necessarily lead to thromboembolism.

The data of this study showed the feasibility of tissue-engineered prostheses to sustain variable mechanical stress conditions temporary occurring at transcatheter deployment. Seeded FBs and ECs showed great retention, ingrowth and ability to form a confluent cell-layer sustaining the pressure of rolling and crimping. The robustness of seeded cells to pressure presents fundamental information for several transcatheter tissue-engineering concepts.

\section{Conclusion}

We believe that using tissue-engineering methods for the development of synthetic minimal-invasive valve will soon present a new generation of promising valve substitutes. This study showed the impact of different types of pressure on tissue-engineered cells. Validation of these results will be done in vitro on the final stented tissue-engineered synthetic heart-valves and reported in the near future.

\section{Acknowledgments}

This work was sponsored by the Federal Ministry of Education and Research (FKZ: 01EZ1107A). The authors would also like to thank Medtronic, Inc. for all their support.

\section{References}

Akhyari, P., Minol, P., Assmann, A., Barth, M., Kamiya, H., \& Lichtenberg, A. (2011). Tissue engineering of heart valves. Chirurg, 82(4), 311-318. http://dx.doi.org/ 10.1007/s00104-010-2031-2

Bleiziffer, S., Ruge, H., Mazzitelli, D., Schreiber, C., Hutter, A., Laborde, J. C., et al. (2009). Results of percutaneous and transapical transcatheter aortic valve implantation performed by a surgical team. European Journal of Cardio-Thoracic Surgery, 35(4), 615-621. http://dx.doi.org/ 10.1016/j.ejcts.2008.12.041

Cebotari, S., Lichtenberg, A., Tudorache, I., Hilfiker, A., Mertsching, H., Leyh, R., et al. (2006). Clinical application of tissue engineered human heart valves using autologous progenitor cells. Circulation, 114, I132-I137. http://dx.doi.org/ 10.1161/circulationaha.105.001065

Chapekar, M. S. (2000). Tissue engineering: Challenges and opportunities. Journal of Biomedical Materials Research, 53(6), 617-620.

Conradi, L., Seiffert, M., Treede, H., Silaschi, M., Baldus, S., Schirmer, J., et al. (2012). Transcatheter aortic valve implantation versus surgical aortic valve replacement: A propensity score analysis in patients at high surgical risk. Journal of Thoracic and Cardiovascular Surgery, 143(1), 64-71.

ElBardissi, A. W., Shekar, P., Couper, G. S., \& Cohn, L. H. (2011). Minimally invasive aortic valve replacement in octogenarian, high-risk, transcatheter aortic valve implantation candidates. Journal of Thoracic and Cardiovascular Surgery, 141(2), 328-335. http://dx.doi.org/ 10.1016/j.jtcvs.2010.08.056

Fischlein, T., Lehner, G., Lante, W., Fittkau, M., Murphy, J. G., Weinhold, C., et al. (1994). Endothelialization of cardiac-valve bioprostheses. International Journal of Artificial Organs, 17(6), 345-352.

Haegerstrand, A., Gillis, C., \& Bengtsson, L. (1992). Serial cultivation of adult human endothelium from the great saphenous vein. Journal of Vascular Surgery, 16(2), 280-285.

Higgins, J., Ye, J., Humphries, K. H., Cheung, A., Wood, D. A., Webb, J. G., et al. (2011). Early clinical outcomes after transapical aortic valve implantation: A propensity-matched comparison with conventional aortic valve replacement. Journal of Thoracic and Cardiovascular Surgery, 142(2), E47-E52. http://dx.doi.org/ 10.1016/j.jtcvs.2011.02.045 
Jux, C., Bertram, H., Wohlsein, P., Brugmann, M., Wuboldt, P., Fink, C., et al. (2002). Experimental ASD closure using autologous cell-seeded interventional closure devices. Cardiovascular Research, 53(1), 181-191. http://dx.doi.org/ 10.1016/s0008-6363(01)00442-4

Kempfert, J., Van Linden, A., Holzhey, D., Rastan, A., Blumenstein, J., Mohr, F. W., et al. (2011). The evolution of transapical aortic valve implantation and new perspectives. Minimally Invasive Therapy \& Allied Technologies, 20(2), 107-116. http://dx.doi.org/ 10.3109/13645706.2011.558101

Kiefer, P., Gruenwald, F., Kempfert, J., Aupperle, H., Seeburger, J., Mohr, F. W., et al. (2011). Crimping May Affect the Durability of Transcatheter Valves: An Experimental Analysis. Annals of Thoracic Surgery, 92(1), 155-160. http://dx.doi.org/ 10.1016/j.athoracsur.2011.03.020

Lalan, S., Pomerantseva, I., \& Vacanti, J. P. (2001). Tissue engineering and its potential impact on surgery. World Journal of Surgery, 25(11), 1458-1466.

Lutter, G., Metzner, A., Jahnke, T., Bombien, R., Boldt, J., Iino, K., et al. (2010). Percutaneous Tissue-Engineered Pulmonary Valved Stent Implantation. Annals of Thoracic Surgery, 89(1), 259-264. http://dx.doi.org/ 10.1016/j.athoracsur.2009.06.048

McVeigh, E. R., Guttman, M. A., Lederman, R. J., Li, M., Kocaturk, O., Hunt, T., et al. (2006). Real-time interactive MRI-guided cardiac surgery: Aortic valve replacement using a direct apical approach. Magnetic Resonance in Medicine, 56(5), 958-964. http://dx.doi.org/ 10.1002/mrm.21044

Mendelson, K., \& Schoen, F. J. (2006). Heart valve tissue engineering: Concepts, approaches, progress, and challenges. Annals of Biomedical Engineering, 34(12), 1799-1819. http://dx.doi.org/ 10.1007/s10439-006-9163-z

Metzner, A., Stock, U. A., Iino, K., Fischer, G., Huemme, T., Boldt, J., et al. (2010). Percutaneous pulmonary valve replacement: autologous tissue-engineered valved stents. Cardiovascular Research, 88(3), 453-461. http://dx.doi.org/ 10.1093/cvr/cvq212

Raja, S. G., \& Navaratnarajah, M. (2009). Impact of Minimal Access Valve Surgery on Clinical Outcomes: Current Best Available Evidence. Journal of Cardiac Surgery, 24(1), 73-79. http://dx.doi.org/ 10.1111/j.1540-8191.2008.00744.x

Schmidt, D., Dijkman, P. E., Driessen-Mol, A., Stenger, R., Mariani, C., Puolakka, A., et al. (2010). Minimally-Invasive Implantation of Living Tissue Engineered Heart Valves A Comprehensive Approach From Autologous Vascular Cells to Stem Cells. Journal of the American College of Cardiology, 56(6), 510-520. http://dx.doi.org/ 10.1016/j.jacc.2010.04.024

Shinoka, T. (2002). Tissue engineered heart valves: Autologous cell seeding on biodegradable polymer scaffold. Artificial Organs, 26(5), 402-406.

Sodian, R., Hoerstrup, S. P., Sperling, J. S., Daebritz, S. H., Martin, D. P., Schoen, F. J., et al. (2000). Tissue engineering of heart valves: In vitro experiences. Annals of Thoracic Surgery, 70(1), 140-144.

Vacanti, C. A. (2006). The history of tissue engineering. Journal of Cellular and Molecular Medicine, 10(3), 569-576. http://dx.doi.org/ 10.2755/jcmm010.003.20

Walther, T., Simon, P., Dewey, T., Wimmer-Greinecker, G., Falk, V., Kasimir, M. T., et al. (2007). Transapical minimally invasive aortic valve implantation - Multicenter experience. Circulation, 116(11), I240-I245. http://dx.doi.org/ 10.1161/circulationaha.106.677237

Weber, B., Emmert, M. Y., Schoenauer, R., Brokopp, C., Baumgartner, L., \& Hoerstrup, S. P. (2011). Tissue engineering on matrix: future of autologous tissue replacement. Seminars in Immunopathology, 33(3), 307-315. http://dx.doi.org/ 10.1007/s00281-011-0258-8

Yacoub, M., Rasmi, N. R. H., Sundt, T. M., Lund, O., Boyland, E., Radleysmith, R., et al. (1995). 14- Year experience with homovital homografts for aortic valve replacement. Journal of Thoracic and Cardiovascular Surgery, 110(1), 186-194. 